\section{La ética de los diseños y métodos alternativos de ensayos clínicos. Una reflexión sobre el Foro Global de Bioética en Investigación del 2017}

La reunión anual del Foro Global de Bioética en Investigación ${ }^{1}$ (GFBR, por sus siglas en inglés) se llevó a cabo en Bangkok, Tailandia, el 28 y 29 de noviembre 2017 y trató sobre la ética de los diseños y métodos alternativos de ensayos clínicos en países de bajos y medianos ingresos. En esta reunión se discutieron otras formas de generar evidencias tales como los ensayos aleatorizados por conglomerado (cluster randomized trials), que consisten en la asignación al azar de grupos en lugar de individuos independientes a una intervención, aquellos en los cuales una intervención se agrega a los conglomerados de manera escalonada (stepped wedge); los ensayos con plataformas adaptativas (adaptative platforms), que permiten modificaciones al ensayo o procedimientos estadísticos del ensayo después de su inicio, sin menoscabar su validez e integridad; y los modelos con infecciones controladas en seres humanos (controlled human infection models o CHIM)(1).

La discusión sobre los diseños alternativos de ensayos clínicos adquirió vigencia durante el brote por el virus del Ébola en África Occidental. Los ensayos clínicos aleatorizados paralelos controlados son tradicionalmente considerados como la forma más sólida de generar evidencia sobre una intervención (2). En respuesta a la percepción de que en ese contexto de emergencia estos diseños eran no éticos, no factibles o carecían del respaldo de las poblaciones locales, se propusieron diseños alternativos, como por ejemplo el ensayo conocido como Ebola ça suffit (3). Si bien es cuestionable que estos estudios sean per se éticamente superiores a los diseños tradicionales $(4,5)$, el análisis sobre nuevos diseños llevó a una mejor comprensión sobre sus virtudes desde un punto de vista científico, por ejemplo, apoyándose en una lógica bayesiana para responder de manera más rápida y eficiente a la pregunta de investigación. En lo que respecta a los métodos alternativos, el brote de zika, y con ello la urgencia de prevenir el síndrome congénito asociado, ha llevado a considerar ensayos clínicos de vacunas en los que se induce la infección a seres humanos de manera controlada.

Contamos ahora, a nivel global, con un bagaje más amplio para hacer investigación en salud, que incluye estos diseños y métodos a los que con frecuencia se llama "alternativos", y que en algunas situaciones podrían ser más eficientes y acaso necesarios para responder a ciertas preguntas de investigación. Sin embargo, hay muy poca familiaridad con estos diseños y métodos en general, particularmente en Latinoamérica. Si bien en la región se realizan algunos ensayos clínicos con estos diseños y métodos, éstos suelen venir listos desde fuera, con frecuencia como ensayos multinacionales de compañías farmacéuticas,

\footnotetext{
Más información sobre el GFBR en http:/ / www.gfbr.global
}

siendo escasa la propuesta de estos nuevos ensayos generados a nivel local. Asimismo, existe una limitación para identificar y dar seguimiento a la implementación de estos estudios en la región, ya que pocos países cuentan con registros completos de ensayos clínicos que permitan dar cuenta de los diseños utilizados en esas investigaciones. Los diseños y métodos alternativos tienen un gran potencial también para la investigación en salud pública; sin embargo, el conocimiento necesario para desarrollar ensayos con estos nuevos diseños, así como los cálculos estadísticos para determinar tamaños de muestra y algoritmos y los modelos matemáticos requeridos para optimizarlos, es aún sumamente limitado en la región.

Al hacer investigación que busque la mejora de la salud y el bienestar de nuestras poblaciones tenemos la obligación ética de buscar los mejores diseños y métodos posibles; ello implica escoger los más adecuados dentro del conjunto completo de diseños y métodos científicos y no limitarnos al subconjunto de ensayos clínicos con el que estamos familiarizados. Más aún, la limitación de recursos para la investigación en nuestra región justifica una preocupación incluso mayor para usarlos de la manera más eficiente, sobre todo si se trata de investigación valiosa para la salud pública, abordando los diseños que permitan arrojar resultados más rápidamente y con menores recursos. Por estos motivos, tenemos la tarea urgente de crear capacidades en la región que nos permitan proponer, evaluar y llevar a cabo estudios con estos nuevos diseños y métodos.

La generación de conocimiento científico debe ir acompañada de la generación de la capacidad de realizar análisis ético con el fin de poder hacer una revisión rigurosa y competente de estos ensayos y métodos, y asegurar su implementación de acuerdo a los más altos estándares éticos. Para lograr esto se requiere, en primer lugar, fortalecer las competencias para realizar dicho análisis sobre la base de las características relevantes de cada protocolo de investigación, en vez de simplemente aplicar una lista de cotejo (checklist). En segundo lugar, es preciso difundir las pautas que brindan orientación para realizar un análisis ético de estos diseños, como las Pautas internacionales para la investigación relacionada con la salud con seres humanos del Consejo de Organizaciones Internacionales de las Ciencias Médicas (CIOMS) que incluyen una pauta dedicada a los ensayos aleatorizados por conglomerado (6), y la orientación previa brindada por la Declaración de Ottawa (7). Es necesario también promover la participación de representantes de la región en la creación de nuevas pautas, como las de infecciones controladas en seres humanos. Ese esfuerzo de generación de capacidades para realizar análisis ético debe ocurrir también en forma simultánea en las autoridades regulatorias que supervisan los estudios y en las instituciones académicas que lideran la investigación en nuestros países.

Todas las partes involucradas en la investigación para la salud (investigadores, comités de revisión ética, autoridades nacionales 
y legisladores, expertos en ética y metodologías de investigación, financiadores y patrocinadores) debemos asegurar que los ensayos clínicos que se llevan a cabo en nuestra región tengan los diseños más aptos científicamente para responder las preguntas de investigación de manera eficiente, y que se lleven a cabo de acuerdo a los más altos estándares éticos. Un esfuerzo decidido para actualizar las capacidades regionales relevantes mencionadas es indispensable para lograrlo.

Declaración. Las opiniones expresadas en este manuscrito son responsabilidad de los autores y no reflejan necesariamente los criterios ni la política de la $R P S P / P A J P H$, la OPS y las otras instituciones a las cuales los autores están afiliados.

\section{Carla Saenz}

Programa Regional de Bioética,

Organización Panamericana de la Salud,

Washington D.C., Estados Unidos de América.

\section{Florencia Luna}

Programa de Bioética, FLACSO Argentina,

Buenos Aires, Argentina.

\section{Sofía P. Salas}

Facultad de Medicina, Universidad Diego Portales,
Santiago de Chile, Chile.

\section{Julio Arturo Canario}

Centro Nacional de Investigaciones en Salud Materno Infantil Dr. Hugo Mendoza (CENISMI), Santo Domingo, República Dominicana.

\section{Jackeline Bravo Chamorro \\ CIDEIM, Cali, Colombia.}

\section{Ricardo Palacios}

Instituto Butantan, São Paulo, Brasil.

\section{Estela Quiroz}

Universidad Nacional Federico Villarreal, Lima, Perú.

\section{Patricia Saidón}

Comisión Nacional Salud Investiga, Ministerio de Salud de la Nación, Buenos Aires, Argentina.

Bertha María Villela

Investigación en Salud, Coordinación Interinstitucional, Ministerio de Salud Pública y Asistencia Social, Guatemala, Guatemala.

\section{REFERENCIAS}

1. Global Forum on Bioethics Research. Background paper: The ethics of alternative clinical trial designs and methods in low- and middle- income country research [internet]. Bangkok: Global Forum on Bioethics in Research [consultada el 30 de enero de 2018]. Disponible en http://www.gfbr.global/wp-content/uploads / 2017/ 04/GFBR-2017-Background-paper_-FINAL.pdf.

2. Guyatt GH, Oxman AD, Vist GE, Kunz R, Falck-Ytter Y, AlonsoCoello P, et al. y GRADE Working Group. GRADE: an emerging consensus on rating quality of evidence and strength of recommendations. BMJ. 2008;336(7650):924-6.

3. Henao-Restrepo AM, Camacho A, Longini IM, Watson CH, Edmunds WJ, Egger M, et al. Efficacy and effectiveness of an rVSVvectored vaccine in preventing Ebola virus disease: final results from the Guinea ring vaccination, open-label, cluster-randomised trial (Ebola Ça Suffit!). Lancet. 2017;389(10068):505-518.

4. Rid A, Miller FG. Ethical rationale for the Ebola "ring vaccination" trial design. Am J Public Health. 2016;106(3):432-5.

5. Joffe S. Evaluating novel therapies during the Ebola epidemic. JAMA 2014; 312(13):1299-1300.

6. Consejo de Organizaciones Internacionales de las Ciencias Médicas (CIOMS) y Organización Panamericana de la Salud. Pautas éticas internacionales para la Investigación relacionada con la salud con seres humanos, 4ta edición. Ginebra: CIOMS, 2016.

7. Weijer C, Grimshaw JM, Eccles MP, McRae AD, White A, Brehaut JC, et al. The Ottawa Ethics of Cluster Randomized Trials Consensus Group. PLoS Med 9(11):e1001346.

Forma de citar Saenz C, Luna F, Salas SP, Canario JA, Bravo J, Palacios R et al. La ética de los diseños y métodos alternativos de ensayos clínicos. Una reflexión sobre el Foro Global de Bioética en Investigación del 2017. Rev Panam Salud Publica. 2018;42:e38. https:/ / doi. org/10.26633/RPSP.2018.38 